\section{THE INFECTIOUSNESS OF TYPHOID FEVER.}

To the Editors of THE LANCET.

SIRS,-I hope you will excuse my boldnesss in venturing to demur to your dictum in THE LANCET of July 28th, p. 245 , on the infectiousness of typhoid fever. I do so in the interests of public health, which must suffer very seriously if the weight of your great authority is thrown in the scale when so momentous a question as to the danger of infection from a particular disease comes to be decided. This is not merely a theoretical point but one of the greatest importance in proper sanitary administration all over the country. Let me appeal in the first place to pathology. Surely typhoid fever is as much a disease of the blood as typhus fever or any of the other exanthemata. The skin, the lungs, the spleen, the liver, and the pharynx come to be affected and not merely the glands of the small intestine. In the case of the pharynx particularly the bacillus typhosus has been found both in the living and dead subjects ; and if so, why should it not be carried in the sputa and expectorated as spray in the breath just as tubercle bacillus is carried from person to person? In the second place, appealing to experience, did not the American commission on the diseases of the Cuban campaign find irrefragable proof of infection by personal contact? I have been constantly seeing cases of typhoid fever for nearly 50 years and have over and over again met with examples of personal infection. Two of my assistants have fallen victims to the complaint in attending patients, and in our hospital here three nurses have been so infected. In my own family one of my assistants infected my own children; and my son, by the stupid bungling of the authorities who placed the enteric fever cases into immediate proximity of the surgical lines in the hospital where he was working, had the trouble so badly as to just escape with his life.

Now, Sirs, I can well believe that this evidence does not completely convince the advocates of water-borne typhoid fever and that form of infection alone. But if there be merely room for the smallest doubt on the point surely it is not far short of criminal not to take every precaution against the spread of the disease by tvery possible channel of any kind. As a medical officer of health I at least would feel guilty in all such cases if I did not attempt to shut the door against every imaginable source of spreading disease.

As to providing opportunities to students to become acquainted clinically with typhoid fever, it must surely be in the eyes of those who do not believe in personal infection of vastly more importance that the raw practitioner should be able to diagnose properly such diseases as small-pox and typhus fever, which he can only become acquainted with in isolation hospitals. If, as cannot be gainsaid, he ought to study these latter complaints by the bedside then he must go where such diseases can be seen, and while so occupied surely he may take advantage of the opportunity to make himself acquainted clinically with typhoid fever as well. On every ground, then, let us exclude this latter disease from general hospitals and let me add-parenthetically-phthisis as well.

I am, Sirs, yours faithfully,

WILLIAM BRUCE, M.D. Aberd.,

Dingwall, July 30th, 1906

Medical Officer of Health of Ross and Cromarty.

\section{DEATH FROM OVERLYING. \\ To the Editors of THE LANOET.}

SIRS,-May I, through the medium of your columns, draw attention to a case of death from overlying in which the external post-mortem appearances were unusually definite. I was called early one Sunday morning to see a child 14 days old who was found dead in bed by its mother. The history briefly was this. After visiting several publichouses the mother, who carried her baby with her, was brought home in a drunken condition by friends. They undressed her and put her to bed and placed the baby close to her right side. This was between the hours of 11 and 12 at night. When she awoke in the early hours of the morning she found her baby dead.

On examining the body at 7.30 on Sunday morning I found rigor mortis well marked. The face was of a uniform dusky hue, and there were large patches of the same colour on the chest, abdomen, and on the front of both legs.
The right forearm was flexed on the arm and the thumb was clenched by the fingers. The right thigh was flexed on the abdomen, and the big toe was strongly extended at the metatarso-phalangeal joint. The limbs on the left side presented nothing noticeable. The body was removed to the public mortuary and a post-mortem examination made at 3.30 P.M. on the same day. The appearances were the same as at the earlier hour, save that rigor mortis was not so marked and that post-mortem stains were forming at dependent parts. The discolouration of the skin had not altered in position. Pressure with the finger on the cheek did not cause blanching of the skin. The lips were purple. A bloody froth which was not noticeable early in the day had now exuded from both nostrils.

The post-mortem appearances in death from overlying are extremely unsatisfactory and the medieal man can often find nothing on which to base an opinion. In this case, however, with the clear history of a healthy infant being placed near its drunken mother, the post-mortem appearances were pronounced. Exudation of a bloody froth from both nostrils is not mentioned as a sign in either of the two textbooks I have at hand (Dixon Mann's and Aubrey Husband's) Dixon Mann writes that the mucous membrane of the larynx and trachea is sometimes found injected and may be covered with frothy mucus, possibly blood-stained (Forensic Medicine, p. 226). He quotes Lamber's, who examined the dead bodies of several children who were killed from compression of the chest in a stampede from a public building and in a majority of these Lambert noticed froth surrounding the mouth and nostrils. Aubrey Husband writes that the presence of froth about the mouth is not constant and is a common occurrence in those dying from natural causes. ${ }^{1}$ It is worth noticing that although the child's nose and mouth presented nothing remarkable at 7.30 A.M. yet at 3.30 in the afternoon a bloody froth extended from both nostrils almost to the chin. General convulsion of all the muscles of the body is one of the stages of asphyxia. The reason why it was noticeable only on the right side may have been because the child lying close by its mother had the left half of its body fixed down by her weight whilst its right was free to contort and twist. The discolouration of the face was a noticeable feature of the case. It resembled the face of a child deeply cyanosed from congenital heart disease, the "morbus cæruleus." The cheek blanched under pressure of the finger but the deep colour gradually returned, and when the body was again examined in the afternoon the face was completely suffused. The body had lain several hours in the mortuary in the dorsal position and post-mortem stains were visible in the dependent parts, but the colour of the face persisted. Turgescence due to throttling passes off, as a rule, shortly after death.

I am, Sirs, yours faithfully,

Exeter, August 3rd, 1906 Joseph A. W. Pereira, M.D. Brux.

\section{SPASMUS NUTANS.}

Io the Editors of THE LANCET.

SIRS,-I have just read with interest the article in THE LANCET of July 28th by Dr. G. F. Still on "HeadNodding with Nystagmus in Infancy." About a year ago a case came under my notice in hospital which differs in some respects from the cases just published by Dr. Still. I must apologise for not giving a definite history, as I have no notes of it and I have to rely on my memory entirely. It was in a girl, aged five years, who was admitted to hospital for the removal of her tonsils and adenoids. Although she did not show any active signs of rickets she was wasted and illnourished and was for that reason kept in hospital for a fortnight after the operation, and it was during the first week that the head-rolling was observed, it gradually lessening under the careful treatment given in hospital.

The exciting cause, however, I feel sure was the presence of pediculi on the scalp. On admission the head was in a terrible state, and it was only after it was cleansed and she was placed on nourishing diet that the cure of the spasmus nutans was accomplished. In addition to the headnodding she exhibited marked symptoms of nystagmus, but I am unable now to state if one eye was more affected than the other-a point so much emphasised by Dr. Still. She 
also had a very bad internal strabismus in both eyes, for which she was wearing convex glasses.

The case seems to me the more interesting now after reading Dr. Still's paper, as the age of the child does not tally with the ages of those reported and also I find no mention of the pediculus capitis as a cause of head-nodding. I may say that it was always when sitting up that she rolled her head, that the movement was from side to side, that the nods were quite $1 \mathrm{CO}$ to the minute, and generally lasted for a period varying between one and two minutes, but that there was no regularity of time between the spasms. I am, Sirs, yours faithfully,

North Kensington, W., August 1st, 1906. HAROLid MoWAT.

\section{MEDICAL PRACTICE IN SOUTH AFRICA AND ITS COMPLICATIONS.}

\section{To the Editors of THE LANCET.}

SIRs, - South Africa may be divided into two parts-the veld where there are no medical men and the towns where there are too many. One consequence of this unequal distribution of the profession is that the farmer on his "plaas" on the lonely illimitable veld has to treat most of the ailments of his household. He has a "pelikaan" for tooth extraction and his wife has her "apotheek"-a box full of the locally renowned Dutch medicines, ${ }^{1}$ such as Haarlem oil, Spanish fly, Hofman's drops, \&c., but these have of late been sufplemented by pink pills, bile beans, liquozone, and the host of modern remedies whose praise is in all the newspapers. Any old " tante" is the midwife for the neighbourhood and any farmer acts as gravedigger and undertaker when required. Sometimes a medical man has to be fetched from a great distance, but only rich families can afford this, for the fees are a guinea an hour, and ten hours are easily spent on the long roads. Medical knowledge gained by recognised methods of study and observation is, as a rule, not very highly esteemed by the "Boeren," who have a decided preference for the "wonderdokter," and in 1899 there was in the Transvaal a famous specimen of the lastmentioned class of practitioner. During the war he was in Cape Town and the Dutch Afrikanders there believed in him. His fame had, in fact, spread all over South Africa. The Afrikanders are like one big family - what happens in the Transvaal is soon known in Cape Town and vice versâ. "Dr. Eugen," as he was called, was quite a celebrity. From far and near the farmers travelled to Pretoria in 1899 to consult him. There was always a file of carts and wagons in his street and inside his door was a crowd peacefully waiting. A consultation always lasted five minutes and the fee was one guinea. As soon as the patient came forward the "dokter" laid both his hands on the former's head and something like an electric current was supposed to pass between healer and subject. The "dokter" knew at once what was wrong. He did not prescribe medicines as he was not possessed of any diploma, but the leading feature of his treatment consisted in regulation of the patient's diet. After his electrical diagnosis he sat in his big armchair and consulted his "spirits" about the different foodstuffs and beverages to be given or withheld. As a rule the farmer had to give up his coffee and wine, which was indeed a very hard trial to the Boer. During winter "Dr. Eugen" left Pretoria for the river Zambesi, where he lived on "drill fish," as they call the torpedo or cramp fish. In this way he got a new store of electricityfor the next season! Sometimes a rich farmer fetched him for an urgent case to his house. This was extremely expensive and the "doctor" would never take the ordinary food placed before the Boer and his family but only a fowl prepared in his own way. Oom Paul Kruger, the late President of the Transvaal Republic, had little faith in this "wonderdokter." He sent for him once but when Eugen began to "consult his spirits" the President asked him to what kind of spirits he was talking. "Are they in heaven?" "I do not think so," was the answer. "Then go," said Oom Paul.

Perhaps there is no part of the world in which patent medicines have such a vogue as in South Africa. Since the greater part of the population come into the world, live, and die without professional aid domestic medicines and some hereditary skill on the part of the farmers have the field much to themselves. No wonder that in this country the newspapers and periodicals, whether daily, weekly, or monthly,

Many pharmacentical chemists announce in gold letters on their windows that they sell Dutch medicines. contain so many advertisements of patent medicines and preparations for invalids. In a recent issue of the Cape limes, our leading newspaper, the following may be counted : (1) Savaresse's Sandal Capsules ; (2) Doan's Kidney Pills ; (3) Wolfe's Schnapps (pictures of 18 tired men!) ; (4) Carter's Liver Pills ; (5) Larola (for the skin); (6) Co-Do (for the mouth); (7) Montserrat; (8) Cockle's Antibilious Pills ; (9) Apiol and Steel Pills ; (10) Steedman's Soothing Powders (for children cutting their teeth); (11) Zam-Buk (in the news columns); (12) Bile Beans (in the news columns); (13) Sheldon's Digestive Tabules (for indigestion, dyspepsia, \&c.); (14) Chamberlain's Cough Remedy ; (15) Jones's Rheumaticuro (for sciatica); (16) Vichy-célestins (for gout, diabetes, \&c.); (17) Koppa (for the hair); (18) Ohicago Cold Cure (cures a cold in 24 hours); (19) Cooper Neuralgia Cure ; (20) Beecham's Pills ; (21) Towle's Pills (invaluable to ladies) ; (22) Wood's Great Peppermint Cure ; and (23) Dr. Shedon's New Discovery. It may here be remarked parenthetically that in the English papers such advertisements in the news columns are always marked $A d v$. Dutch papers may take them without any addition and as a rule with deceptive headlines. Once there was almost a quarrel between the editor and the director of ons Land; the former said: "My readers must see $A d v$. under such articles." "No," said the latter, "our shareholders have our first care." Dr. Sanden's electric belt occupies an advertisement space of about 50 square inches in every issue of our leading papers, Datch and English, but the pink pills have been much less con. spicuous of late. Perhaps this is caused by the harshness of our legislators. Before the new Custom tariff came into force on May 25th the agent for the pink pills paid only a trifling ad valorem duty on $7 d$. per 1000, this being the value as per invoice. But now he has to pay $£ l$ sterling for one pound avoirdupois, which is a very different thing. Of course, the farmers are the best customers for patent medicines, but as some of them read little more than their Bibles and a weekly church paper-De Kerkbode or $D_{e}$ Vereeniging -it is no wonder that even these religious papers get a good share of advertisements from the patent medicine vendors, so that next to a highly poetical and edifying explanation of some passage of Holy Writ there may be found a most prosaic paragraph on diseases and their treatment. Every druggist keeps a fairly complete stock of patent medicines as far as he can get hold of them, but some nostrums are not yet to be found in any drug store, because the agents do not wish to surrender any portion of their profits.

Medical men are not popular with the people, not even with the town people, partly because they are said to charge very high fees and partly because they are supposed to be required only for treating diseases of the teeth and for performing operations in which cutting and sewing are necessary. In cases of internal ailments the general idea is that the cheapest and easiest way is to go to a chemist and ask his advice. In 1901 and 1902 there was perhaps as much venereal disease in Cape Town as in any town on the globe, and most of these cases of syphilis and gonorrhœea were treated without a medical man. One druggist had 500 venereal patients in a month and all dealers in medicinal substances laid in full stocks of mercurials and santal midi to be disposed of to customers coming for advice and treatment.

As a rule the Boers succeed very well in rearing their large number of children. At Standerton there is a family with 29 children. When $I$ lived in a farming district in the Transvaal for a year I found that between 10 and 15 children in every house was the average and very few infants died. In Cape Town, however, more than 50 per cent. of the children die in their first year and even among the white people the death-rate is large. Our town council discussed the question in January last with the result that a duly qualified nurse now goes round to the houses where there are infants, examines the little ones, and gives the parents good advice.

Cape Town. I am, Sirs, yours faithfully, C. J. VAN RIJN.

\section{CARDIFF AND SWANSEA HOSPITALS.}

\section{Io the Editors of THE LANCET.}

SIRS,-The grounds for your unfavourable criticism in THE LANCET of July 28th of the management of the Swansea Hos pital as compared with that of Cardiff for the year 1905 appear to be the relative cost per bed as furnished by your correspondent. These were-Swansea, £71 19s.; Cardiff, 